\section{An Automatic Device for Controlling Hot Air Ovens}

\author{
R. E. DAVIS
}

From the Department of Haematology, Royal Perth Hospital, Perth, Western Australia

(RECEIVED FOR PUBLICATION FEBRUARY 21, 1959)

The automatic device to be described offers the following advantages when fitted to hot air sterilizers:

The oven may be switched on and left, when the temperature will rise to $160^{\circ} \mathrm{C}$. or any other preset temperature. The temperature will be maintained for any preset length of time up to one hour, and after this the unit will switch off the power. The complete cycle is automatic so that the need for an operator to watch the temperature and the clock is eliminated. The oven may be switched on just before the laboratory closes in the evening; it will then complete the warming up and sterilizing cycle automatically.

The device (Fig. 1) consists of a relay with two pairs of contacts. The lower contacts are closed except when the relay is energized; the upper contacts are used to complete the energizing circuit. The relay is wired to the hot air oven as shown, one wire going to the power and the other to the sensitive side of the thermostat. The clock section of a Venner process timer (model P.T.4) is connected to the power via the lower relay contacts and the process timer switch section is connected between the main supply and the oven. Controls include stop and start buttons and an automatic/manual switch. A pilot light indicates when the relay is energized.

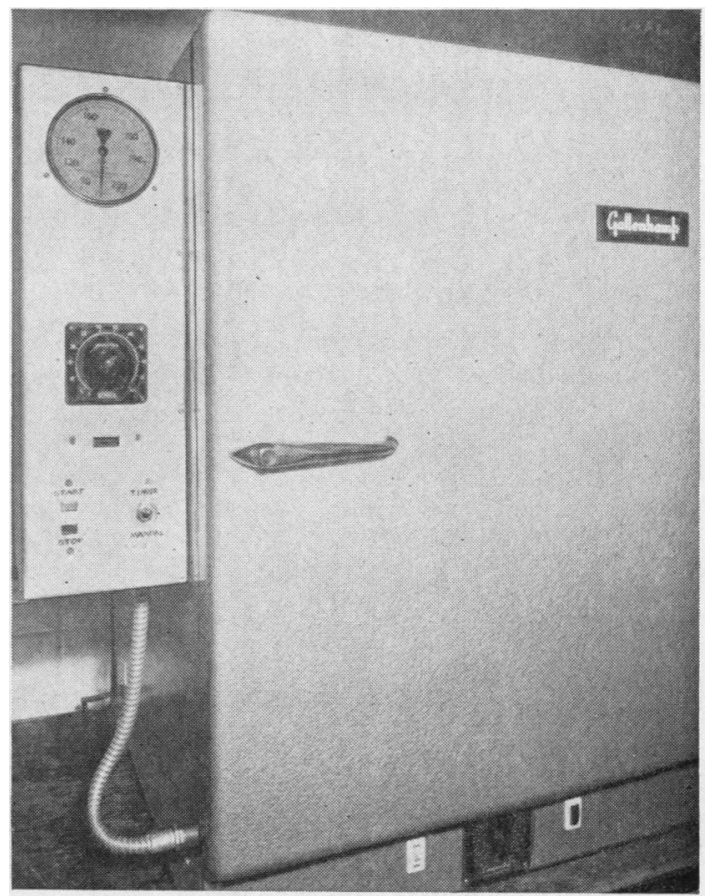

FiG. 2.-Complete unit fitted to the hot air sterilizer. The thermometer is not part of the circuit.

The power is switched on and the "start" and time switch buttons are pressed. The start button sets the relay with the upper contacts closed (E, Fig. 1). The oven temperature will now rise until the thermostat is activated and opens the circuit to the heaters and the relay. Opening the relay circuit will complete the timer circuit. The timer may be set for any period up to one hour, after which it will switch off the current.

FIG. 1.- The circuit to the right of $A$ is that already incorporated in the Gallenkamp hot air sterilizer. On the left of $A$ are the additions required for automatic operation. $A=$ mains plug; $\mathbf{B}=$ single pole two-way switch; $\mathbf{C}=$ start button (pressing this button makes the contact); $\mathbf{D}=$ manual stop button (pressing this button breaks the contact); $\mathbf{E}=$ relay; $\mathbf{F}=$ pilot light; $\mathbf{G}=$ Venner process timer (P.T.4); $1-3=$ power switch; $3-4=$ thermostat ; $\mathrm{H} 1$ to $5=$ heaters; $2-4=$ pilot light ; $M=$ fan motor.

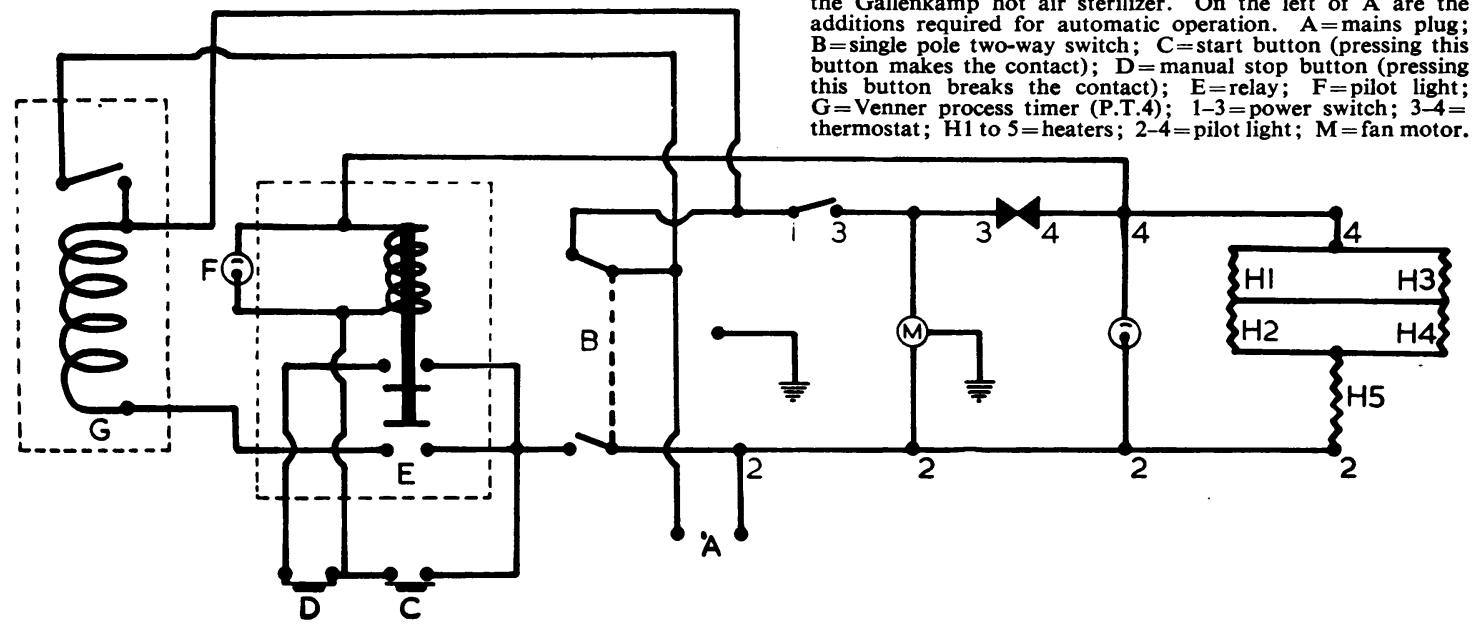

